\title{
Caracterização da Cadeia Turística do Mato Grosso do Sul
}

\section{Characterization of the Tourist Chain of Mato Grosso do Sul}

\author{
Lis Damaceno de Oliveira ${ }^{1}$ \\ Luiz Eustáquio Lopes Pinheiro ${ }^{2}$ \\ Ido Luiz Michels ${ }^{3}$
}

\begin{abstract}
Resumo
A pesquisa abrangeu três pólos turísticos do Mato Grosso do Sul: Campo Grande, Bonito e Corumbá, objetivando identificar as formas de interação entre os agentes econômicos, sociais e políticos, bem como as forças externas que interferem nos serviços turísticos. Os resultados obtidos evidenciaram que a cadeia produtiva do turismo no Estado apresenta problemas relacionados à infra-estrutura básica e turística e à baixa qualificação da mão-de-obra, somados a ausência de uma política estadual própria. Especificamente foram identificados pontos de estrangulamento comuns nos três pólos estudados, destacando-se: a deficiência em recursos humanos preparados e capacitados, desarticulação do empresariado local e ausência de um sistema para quantificação do turismo. As conclusões indicam que a falta de política apropriada prejudica a organização da atividade, estimula a concorrência entre os pólos turísticos estaduais, afetando diretamente na competitividade de Mato Grosso do Sul perante os outros destinos turísticos nacionais e internacionais.
\end{abstract}

Palavras-chave: ecoturismo; Pantanal; desenvolvimento local; cadeia produtiva.

\begin{abstract}
The research was realized in three main tourist regions for Mato Grosso do Sul, namely: Campo Grande, Bonito and Corumbá, and objectified to identify the forms of interaction between the economic, social and politicians agents, as well as how the external forces intervene in the tourist service. The obtained results had evidenced that the tourism productive chain in stats shows related problems the basic and tourist infrastructure and low qualification of the local man power, added the absence of one state politics of tourism. Specifically common points of strangulation in the three studied tourist regions had been identified, being distinguished: the already mentioned deficiency in human resources prepared and enabled, the disarticulation of local entrepreneurs and the absence of a system to quantify the tourism in each tourist region. The conclusions indicate that the lack of appropriate politics harms the organization of the activity, resulting in stimulation to the competition between the state tourist regions, affecting directly in the competitiveness of Mato Grosso do Sul before the other national and international tourist destinations.
\end{abstract}

Keywords: ecotourism; Pantanal, Local Development, Productive chain.

\footnotetext{
1 Bacharel em Turismo, Mestre em Meio Ambiente e Desenvolvimento Regional. E-mail: lisdamaceno@yahoo.com.br

${ }^{2}$ Médico Veterinário, Mestre, Doutor e Livre Docente, Professor da UNIDERP. E-mail: lepinheiro@uniderp.br

${ }^{3}$ Economista, Mestre e Doutor em Geografia Humana, Professor da UNIDERP. E-mail: idomichels@uol.com.br
} 


\section{Introdução}

Em 2006 os turistas estrangeiros gastaram no Brasil US\$ 4,3 bilhões, superando em 11,77\% os US\$ 3,8 bilhões registrados em 2005 (Mtur, 2006). Neste contexto, o estado de Mato Grosso do Sul ganhou notoriedade por seu significativo potencial turístico, sobretudo, no segmento do ecoturismo, dada à exuberância de suas riquezas naturais. Segundo a Secretaria de Estado de Planejamento e de Ciência e Tecnologia (2003), pelo menos 40\% dos atrativos turísticos do Estado são naturais e ecológicos; $16 \%$ estão distribuídos na categoria históricoculturais; $28 \%$ estão na categoria folclore; $6 \%$ referem-se à realizações técnicas e científicas e $10 \%$ encontram-se na categoria de eventos programados.

Em 2005, o Estado recebeu 519.752 turistas, representando um aumento de 23,9\% em relação ao ano anterior (419 mil turistas), segundo Silveira (2006). Estes números demonstram que o turismo no Estado está crescendo gradativamente, contudo ainda enfrenta dificuldades, principalmente na identificação dos agentes que interagem no processo produtivo e na mensuração de seus impactos econômicos. Logo, a organização e desenvolvimento do turismo em Mato Grosso do Sul, apesar de seu crescimento recente, com destaque para Bonito, Campo Grande e Corumbá, indica que a cadeia produtiva do turismo poderia ser mais eficiente e competitiva, se houvesse uma maior integração entre os diversos elos que a compõe. Desta forma, esta análise aponta para a estruturação e avanços dessa cadeia no estado, notadamente nos três pólos destacados acima, mas também enfatiza a necessidade de superar evidentes lacunas destacadas neste estudo.

A cadeia produtiva do turismo do Mato Grosso do Sul, apesar das diversas limitações, existe e vem se desenvolvendo, centrada muito mais em regiões isoladas, como Campo Grande, Serra da Bodoquena e Corumbá, do que como decorrência de uma efetiva política pública e privada para o Estado como um todo. Isto contribui para gerar e manter deficiências, as quais, se adotada ações mais eficazes (públicas e privadas), poderiam ser eliminadas, contribuindo para integrar os diversos segmentos e ampliar a competitividade.

Diante disso, estudar e caracterizar a cadeia produtiva do turismo em Mato Grosso do Sul vem ao encontro das necessidades vivenciadas não só no contexto estadual, mas também no contexto nacional, mostrando-se ser etapa primordial para organização efetiva e desenvolvimento da atividade turística. Para tanto, esta pesquisa ${ }^{4}$ foi desenvolvida, em forma

\footnotetext{
${ }^{4}$ Reiteramos nossos agradecimentos ao curso de Mestrado em Meio Ambiente e Desenvolvimento Regional da Universidade para o Desenvolvimento do Estado e da Região do Pantanal - Uniderp e a Fundação Cândido Rondon que possibilitaram através do apoio logístico e financeiro a concretização dessa pesquisa.
} 
de um estudo fenomenológico, adotando a ferramenta de análise de formulação e estruturação das cadeias produtivas aplicada ao agronegócio, que consiste em descrever as operações de produção responsáveis pela transformação da matéria-prima em produto acabado.

\section{Referencial Teórico}

\subsection{O conceito de turismo}

Em 1992, o Instituto Brasileiro de Turismo (EMBRATUR), passou a considerar o turismo como atividade econômica, gerada pelo deslocamento voluntário e temporário de pessoas para fora da sua localidade de residência fixa por qualquer motivo, excetuando-se o exercício de atividade remunerada. É composta pelo conjunto de transações, compra e venda de serviços turísticos efetuadas pelos/entre os agentes econômicos do turismo. Contudo, como afirmou Zimmermann (1996), o turismo é também um fenômeno social, composto pelo homem (autor do turismo), pelo espaço (substrato para a realização do turismo) e pelo tempo (elemento temporal consumido pela própria viagem - deslocamento - e pela estada no destino). Posteriormente, Barreto (2003) lembrou ainda, que o turismo é movimento de pessoas e atendimento das necessidades dos que viajam ou não, pressupondo assim, uma interação entre o turista e o núcleo receptor.

Indo mais além, numa visão humanista e holística do turismo Jafar Jafari e Beni (2003) afirmaram que a atividade turística foca o homem fora do seu local de habitação. Neste ambiente, ele é influenciado diretamente por fatores de realização pessoal, social, motivacional, econômica, cultural, ecológica e científica. Neste particular, o turismo é ainda o elemento gerador de impacto sobre os ambientes físicos, econômico e sociocultural da área receptora.

O conceito de turismo, admitido do ponto de vista formal e que serve como ponto de referência para a elaboração das estatísticas internacionais foi o estabelecido pela Organização Mundial do Turismo (OMT), em 1994. Define-se o mesmo, como o conjunto de atividades realizadas pelas pessoas durante suas viagens e estadas, (período inferior a um ano), em lugares diferentes de sua residência fixa, motivados por lazer, negócios e outros (OMT, 2001). 
Apesar das diferentes definições acerca da atividade turística, observa-se a presença comum de três elementos: o espaço físico, o tempo e o indivíduo. Configurando assim, os aspectos básicos componentes do turismo, conforme descreveu Abreu (2002).

\subsection{A abordagem econômica do turismo}

Segundo Balanzá e Nadal (2003) o turismo pode ser descrito como a combinação de bens e serviços, de atrativos e infra-estruturas, ordenados de maneira que ofereçam vantagens aos clientes, que consigam satisfazer suas percepções e expectativas, e que requer empresas que se dediquem a realizar essas atividades que o tornam possível. Dessa forma, o mercado turístico seria composto por quatro elementos básicos que devem ser considerados conjuntamente como sistema e que evoluem de forma dinâmica, a saber: demanda; oferta; o espaço geográfico e os agentes intervenientes ou os operadores de mercado.

Com respeito aos bens e serviços, deve-se mencionar a existência dos de ordem tangível e intangível (Beni, 2003). Para o autor, a parte tangível é o produto global em si, tal como é oferecido pelos produtores. Já a intangibilidade advém das percepções e expectativas geradas pelos consumidores. Nos produtos tangíveis ambas as partes têm, em geral, a mesma importância. Contudo, no turismo, a parte intangível é mais importante do que a outra, porque quando os consumidores/usuários se dispõem a comprar o produto turístico pautam a decisão de compra nas suas percepções, já que o produto turístico não é palpável e só pode ser completamente consumido no destino.

Ainda no mesmo contexto, Beni (2003) afirmou ser o produto turístico resultado do processo produtivo da atividade fim, a qual consiste na exploração dos recursos geográficos, isto é, atrativos naturais e culturais de determinado país, fazendo uso de tecnologia, trabalho e capital. Especificamente no turismo, o momento de produção coincide com a distribuição e muitas vezes com o de consumo, haja vista que o produto turístico é produzido e consumido no mesmo local, sendo o consumidor quem se desloca para a área de consumo.

Combinados entre si, os diferentes tipos de serviços turísticos, agregam valor, criando o produto turístico, que é composto por dois elementos básicos: atrativos e infra-estrutura turística, como exposto por Balanza e Nadal (2003). Segundo Vaz (1999 apud Cordeiro, 2001), na produção, distribuição e consumo do produto turístico surgem várias empresas diferentes umas das outras, resultando a grande dificuldade de padronização e qualidade do produto, pois envolve uma combinação entre diversos serviços e equipamentos. Ainda segundo o mesmo autor, como a prestação de um bom serviço turístico está interligada às 
demais atividades econômicas, cria-se uma relação de interdependência de vários fornecedores. Como conseguinte, a formação do produto turístico exige a interação de dois níveis - bens turísticos e serviços - que não devem ser vistos como duas partes distintas, mas sim como dois níveis do produto turístico que se articulam e necessitam um do outro.

\subsection{Cadeia produtiva do turismo}

Para fins de ordenamento dos vários segmentos adjuntos ao turismo, optou-se por utilizar as definições de cadeias produtivas comumente utilizadas no agronegócio. Assim, o conceito norteador é aquele descrito por Batalha (2001), que se refere às relações de contrato ou interdependência entre segmentos que configuram determinada cadeia de produção, formada em torno da produção dos itens a ele pertinentes.

Contudo, Massari (2005) alertou que tais conceitos de cadeia produtiva estão relacionados à atividade industrial e não aos serviços, setor no qual o turismo está inserido. A autora afirmou ainda que ao estabelecer o modelo de cadeia produtiva do turismo deve-se considerar a atividade turística como um fenômeno único e multi-setorial. Logo, a cadeia produtiva do turismo congrega os elos que se articulam, desde o uso dos equipamentos e da infra-estrutura, do destino turístico indo até o fator que gera o estímulo e a decisão de compra do consumidor (marketing e promoção turística). Finalmente, ainda segundo Massari (2005) o turismo é uma combinação de uma série de outras atividades econômicas integradas, na qual é criada uma oferta e uma demanda, que pode existir ou até ser estimulada.

Embora conhecedores que somos de eventuais controvérsias como as apontadas acima em relação as possíveis limitações teóricas do instrumental de cadeias produtivas para a análise da atividade turística, entende-se que a mesma em que pese essas possíveis limitações, não comprometem a essência desta reflexão. Antes pelo contrário, pois seus fundamentos de análise são notadamente multi-setoriais e interdisciplinares, o que permite uma análise que traga de fato as complexidades da cadeia produtiva do turismo, pois abordagens disciplinares (econômicas, geográficas, administrativas, etc.), são por elas mesmas restritivas em relação a abordagem teórica pela qual se optou nesta reflexão.

Sendo assim, conforme, Balanzá e Nadal (2003) a cadeia produtiva do turismo é composta pelo trade (mercado) turístico, que é formado principalmente pelos operadores do mercado e por empresas e organizações, cuja função principal é facilitar a relação entre a oferta e a demanda. Entram nessa consideração as agências de viagens, as companhias de transporte 
regular e os organismos públicos e privados que, mediante seu trabalho profissional, se ocupam da organização e/ou promoção do turismo.

\section{Material e Método}

O estudo de caráter fenomenológico utilizou a abordagem de análise de cadeia de valor, que segundo Fleury e Fleury (2005), enfatiza as relações que as organizações estabelecem entre si, considerando as conseqüências das relações entre as empresas e como elas são governadas.

A técnica de coleta de dados de caráter qualitativo contemplou levantamento de informações secundárias (pesquisa bibliográfica), entrevistas não dirigidas, com representantes do trade turístico estadual, e discussões em grupos nos três pólos estudados, a saber: Campo Grande, Serra da Bodoquena e o Pantanal, por serem estas, as regiões consideradas prioritárias para o desenvolvimento da atividade turística segundo o Programa de Regionalização do Turismo Roteiros do Brasil.

Entre os meses de agosto e setembro de 2006 foram realizadas entrevistas não dirigidas com empresários, representantes de entidade de classe e representantes governamentais que se mostraram importantes para coleta das informações relacionadas a problemática da pesquisa. Foram entrevistados três representantes de agências de viagem; um representante das operadoras de turismo; um representante da Fundação de Turismo de Mato Grosso do Sul; dois representantes de entidades de classe (Associação Brasileira das Agências de Viagens, seccional Mato Grosso do Sul - ABAV/MS, e Associação Brasileira da Indústria de Hotéis, seccional Mato Grosso do Sul - ABIH/MS) e um representante do Campo Grande Pantanal Convention \& Visitors Bureau.

A preocupação na escolha desses sujeitos pautou-se na representatividade que eles possuem perante o setor, e não na quantidade, tendo em vista, que em um estudo qualitativo tal abordagem se justifica. Para a escolha das agências de viagens utilizaram-se os critérios: tempo de existência do mercado, venda de pacotes nacionais e internacionais e o fato de atuarem como agências emissivas e/ou receptivas. Já para a escolha da operadora de turismo o critério de escolha foi o tamanho da empresa, que tem a sede em Campo Grande e uma filial em um dos outros pólos estudados. A Fundação de Turismo de Mato Grosso do Sul foi selecionada por ser o órgão oficial que coordena as atividades ligadas ao turismo no estado. A escolha pelos representantes da ABAV/MS e ABIH/MS justifica-se por serem essas entidades representantes de dois dos principais componentes do turismo. Por fim, o critério de escolha 
do Campo Grande Pantanal Convention \& Visitors Bureau, deu-se por ser o primeiro convention criado no estado e também por ser a instituição responsável pela captação de eventos.

Foi utilizada também como técnica de coleta de dados nos três municípios, as discussões em grupo, realizadas nos meses de outubro e novembro de 2006. Flick (2004) aponta como vantagens desse método a possibilidade das correções por parte do grupo caso algumas visões não estejam corretas, não sejam socialmente compartilhadas ou ainda sejam radicais, permitindo a validação e a elucidação de pontos de vista. Dessa forma, o grupo torna-se um instrumento de reconstrução de opiniões individuais de forma mais adequada.

Para a formação dos grupos foram enviados convites, via correio, e-mail e fax, aos empresários do setor de turismo, gestores públicos, entidades de classe e instituições de ensino superior de cada localidade. Os grupos, que somaram 60 participantes, eram formados por empresários do setor turístico, presidentes de entidades de classe, representantes de instituições de ensino superior e representantes da gestão pública municipal. Primou-se pela composição de um grupo heterogêneo, tendo em vista, que foi necessário coletar as percepções de sujeitos que atuam em áreas que afetam direta ou indiretamente o turismo.

As discussões de grupo realizadas durante a pesquisa seguiram o padrão esquemático apresentado por Flick (2004). No caso, o estímulo para a discussão foi uma apresentação em PowerPoint, contendo as informações coletadas na pesquisa bibliográfica e documental, o desenho-proposta para a cadeia produtiva do turismo em cada região, alguns pontos fortes e fracos e as situações de conflito identificadas anteriormente. A medida que os tópicos iam sendo apresentados, eram discutidos abertamente pelo grupo.

Durante as entrevistas não dirigidas e as discussões em grupo buscou-se obter informações sobre o turismo em Mato Grosso do Sul, tais como pontos fortes, pontos fracos, canais de distribuição e comercialização do produto turístico, atores envolvidos na cadeia produtiva do turismo sul-mato-grossense, fatores externos e internos que afetam a competitividade da cadeia.

Os dados obtidos foram analisados qualitativamente, fornecendo as bases para caracterizar os resultados comparativos. 


\section{Resultados e Discussão}

\subsection{O turismo em Mato Grosso do Sul}

A atividade turística ainda tem pouca representatividade para a economia do Estado, considerando que, em 2003, as atividades relacionadas (Alojamento e alimentação e Transporte e armazenagem) representaram apenas 4,44\% do total do PIB, somando R $\$ 777,53$ milhões. Em 2004, o setor terciário apresentou um crescimento de 3,16\%, impulsionado pelas atividades de comunicação, transportes, outros serviços e serviços domésticos. As atividades ligadas ao turismo apresentaram leve crescimento, passando a ser responsáveis por $4,59 \%$ do PIB estadual neste período (Seplanct, 2003 e 2006).

De acordo com o Ministério do Turismo, Mato Grosso do Sul, possui, cadastradas, 192 agências de turismo, 142 meios de hospedagens, 89 transportadoras turísticas, 19 organizadoras de eventos, totalizando 443 empreendimentos turísticos (Mtur, 2006).

Para melhor caracterizar a atividade no Estado, os resultados de fluxo turístico de 1995 a 2005, construiu-se o Quadro 1, o qual mostra crescimento gradativo até o ano de 2000, seguindo-se queda acentuada. Entretanto, quando comparado com 2004, o número de turistas em 2005 (519.752 turistas) cresceu em 23,9\%, representando um avanço de quase dez pontos percentuais acima do incremento médio nacional no mesmo período, que fora de $12,5 \%$. A receita estimada total foi de R $\$ 127$ milhões, sendo o desembolso médio individual/dia de R\$ 90,00, para o ano de 2005 (Júnior, 2006).

Quadro 1- Fluxo de turistas em Mato Grosso do Sul

\begin{tabular}{|lrrrrrrr|}
\hline \multicolumn{7}{|c|}{ Principais Pólos e Fluxos de Turistas em Mato Grosso do Sul - 1995-2000 } \\
\hline Localidade & $\mathbf{1 9 9 5}$ & $\mathbf{1 9 9 6}$ & $\mathbf{1 9 9 7}$ & $\mathbf{1 9 9 8}$ & $\mathbf{2 0 0 0}$ & $\mathbf{2 0 0 4}$ & $\mathbf{2 0 0 5}$ \\
\hline Bonito (Gruta) & 29.811 & 38.800 & 51.717 & 64.400 & 81.600 & $\ldots .$. & $\ldots . .$. \\
Corumbá (Pantanal) & 156.394 & 203.000 & 243.900 & 243.900 & 380.600 & $\ldots .$. & $\ldots .$. \\
Ponta Porã (Paraguai) & 144.000 & 172.800 & 207.300 & 229.000 & 301.600 & $\ldots .$. & $\ldots .$. \\
Demais pólos turísticos & 77.000 & 92.400 & 110.800 & 137.000 & 168.300 & $\ldots .$. & $\ldots .$. \\
\hline TOTAL & $\mathbf{4 0 7 . 2 0 5}$ & $\mathbf{5 0 7 . 0 0 0}$ & $\mathbf{6 1 3 . 7 1 7}$ & $\mathbf{6 7 4 . 3 0 0}$ & $\mathbf{9 3 2 . 1 0 0}$ & $\mathbf{4 1 9 . 0 0 0}$ & $\mathbf{5 1 9 . 7 5 2}$ \\
\hline
\end{tabular}

FONTE: SEPLANCT (2003); JÚNIOR (2006)

OBS.: Os números de 2001, 2002 e 2003 não estão disponíveis.

Conforme pesquisa encomendada pelo Ministério do Turismo, os principais estados emissores de turistas para o Mato Grosso do Sul são, em primeiro lugar, São Paulo (52,7\%), seguido 
pelo próprio Mato Grosso do Sul $(13,4 \%)$. O Paraná ocupa a terceira posição com a margem de $12,5 \%$. Minas Gerais e Rio Grande do Sul estão em quarto e quinto lugar, respectivamente, com $6,4 \%$ e $5,9 \%$, cada. O Rio de Janeiro ocupa a sexta posição com 3,2\%, seguido com pequena diferença pelo Mato Grosso (3\%). São ainda, regiões emissoras de turistas para o Estado, o Distrito Federal, Rio Grande do Norte e Santa Catarina.

O Programa de Regionalização do Turismo - Roteiros do Brasil (Mtur, 2004) divide o estado de Mato Grosso do Sul em três regiões turísticas: Campo Grande e Região, Pantanal e Serra da Bodoquena.

\subsection{Cadeia produtiva do turismo do Mato Grosso do Sul}

A cadeia produtiva do turismo (cadeia turística) do Mato Grosso do Sul foi idealizada a partir da cadeia produtiva do agronegócio, ilustrada na Figura 1.

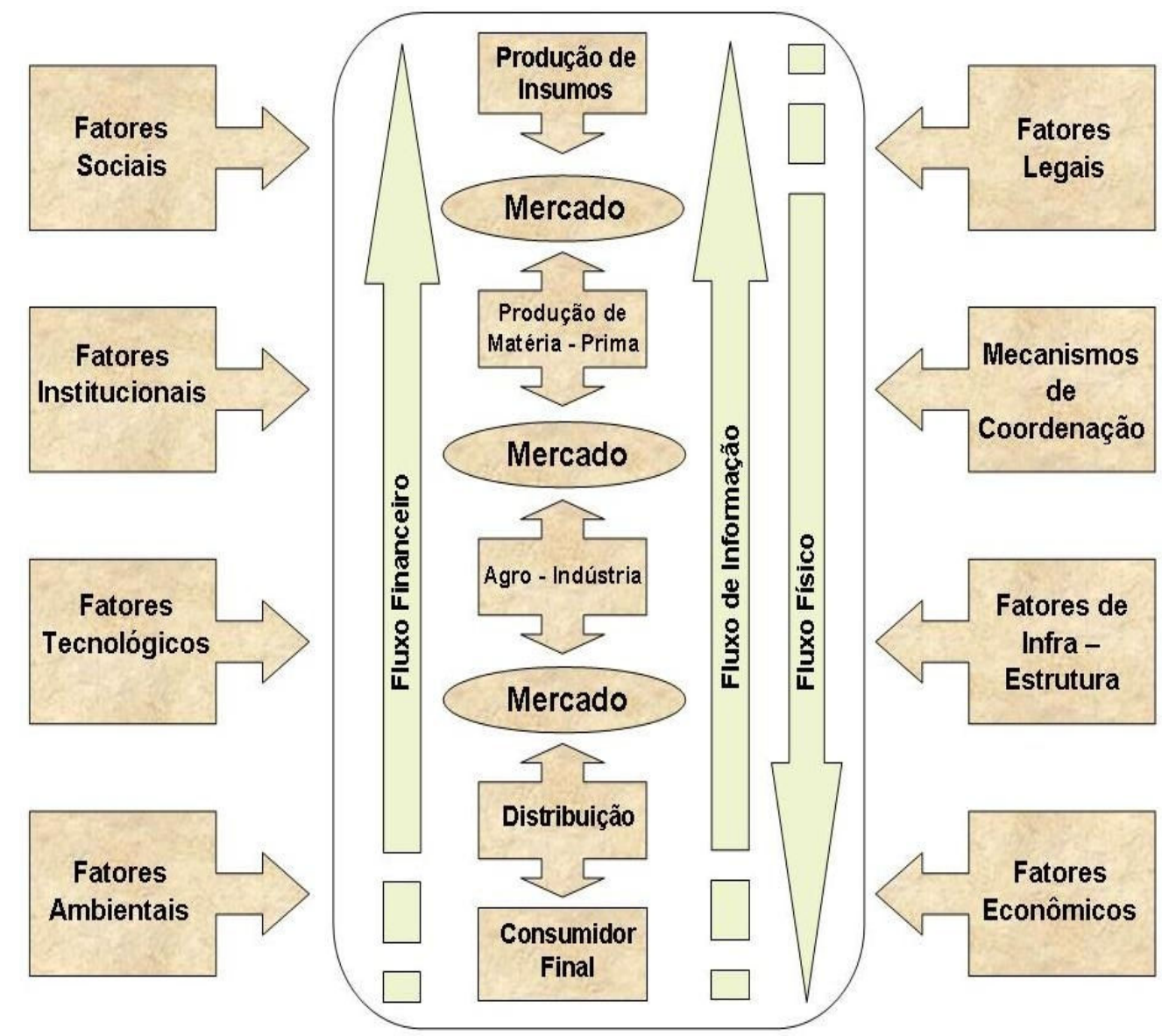

Figura 1- Exemplo Esquemático da Cadeia Produtiva do Agronegócio 
Uma análise de cadeia produtiva genérica caracteriza toda a segmentação da produção de determinado produto, desde o produto final até matéria-prima, em três macrossegmentos: Comercialização (empresas que estão em contato direto com o cliente final e que viabilizam o consumo e o comércio dos produtos finais); Industrialização (empresas responsáveis pela transformação das matérias-primas em produtos finais destinados ao consumidor); e, Produção de matérias-primas (empresas que fornecem as matérias-primas iniciais para que outras empresas avancem no processo de produção do produto final).

Essa ferramenta de análise reforça ainda o papel exercido pelo consumidor, uma vez que, a decisão de compra dos produtos depende de referenciais básicos, tais como preço e qualidade. Sendo assim, as manifestações dos consumidores finais caracterizam os fios condutores de ações a serem desenvolvidas pelos demais elos da cadeia, pois são seus desejos e preferências os pontos que sinalizam o início do caminho a ser percorrido.

A Figura 2 representa a cadeia produtiva do turismo do Mato Grosso do Sul, bem como as suas principais características ilustrando como ocorre o processo de produção do turismo no Estado. 


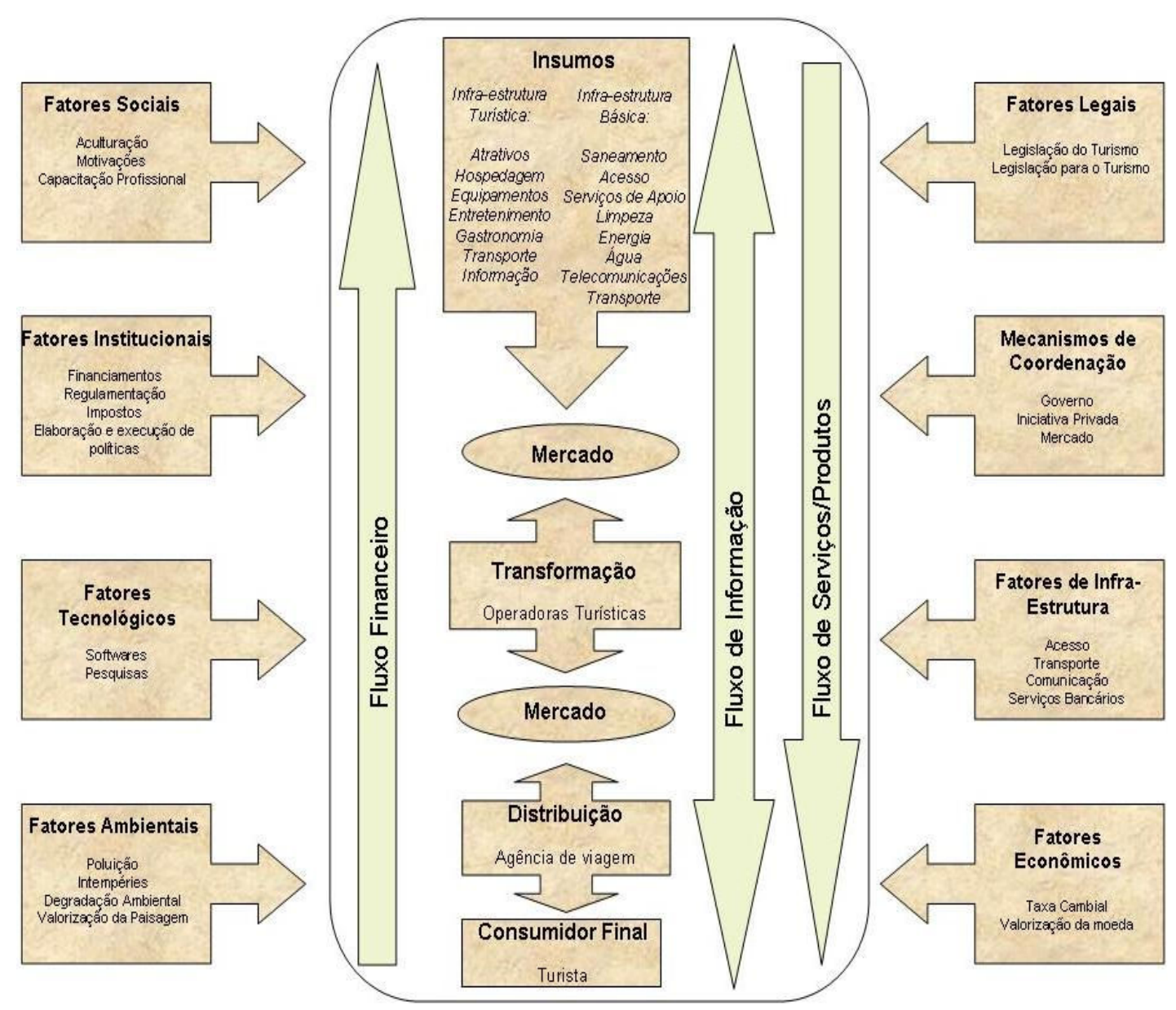

Figura 2. Cadeia produtiva do turismo do Mato Grosso do Sul.

Pana análise da cadeia produtiva do turismo partiu-se, portanto, da concepção genérica de cadeia produtiva comumente adotada para o agronegócio, sendo a mesma segmentada em três macrosegmentos, com a diferença que o macrosegmento de Industrialização é, nesta caracterização, intitulado de Transformação ${ }^{5}$, pois o turismo é serviço e não indústria. Os outros dois macrosegmentos são: Produção de matérias-primas (para o turismo insumos e matérias-primas foram considerados conjuntamente) e Comercialização, dada algumas características da atividade turística como: a intangibilidade e a produção e o consumo simultâneos (ocorrem no mesmo espaço e tempo). Os mercados existentes são três, a saber: mercado entre os produtores de insumo e os transformadores (operadoras de turismo); mercado entre os transformadores e distribuidores e, mercado entre os distribuidores e os consumidores finais.

\footnotetext{
${ }^{5}$ No item Transformação listou-se somente as Operadoras Turísticas, pois se considerou a forma clássica de concepção de uma viagem. Sendo assim, não foram citados os deslocamentos realizados sem intermediação.
} 
Além disso, o Fluxo de Informações é bidirecional, uma vez que a informação é o grande diferencial na garantia da satisfação dos consumidores. A seta indicativa do Fluxo de Informações é bidirecional porque, no turismo, a informação parte tanto dos consumidores para os empresários quanto dos empresários (principalmente as agências de viagens e operadoras turísticas) para os clientes. É válido ressaltar que a informação tem papel decisivo na escolha do destino e na efetivação da compra de um produto turístico.

O Fluxo Financeiro permanece unidirecional (consumidor-empresários), pois é o turista (consumidor final) que movimenta a cadeia.

Devido a intangibilidade do produto turístico a seta indicativa do Fluxo Físico foi renomeada para Fluxo de Serviços/Produtos. Ela representa uma relação de encadeamento entre os agentes da cadeia, ilustrando a ordem de alocação dos atores/elementos necessários na formatação do produto turístico.

No macrosegmento dos Insumos, foram alocados os principais elementos necessários para que o turismo aconteça em determinada localidade. São considerados como insumos da atividade turística, a infra-estrutura turística e a infra-estrutura básica. A infra-estrutura turística é composta pelos atrativos, hospedagens, equipamentos, locais de entretenimento, gastronomia, transporte, informação turística e outros. Já a infra-estrutura básica abrange o saneamento, acesso, serviços de apoio, energia, água, telecomunicações, transporte etc.

O macrosegmento de Transformação é composto pelas operadoras de turismo. São elas as responsáveis por organizar os insumos e formatar os produtos e pacotes turísticos.

As agências de viagem constituem o macrosegmento de Distribuição, ficando sob sua responsabilidade o repasse das informações e a comercialização dos produtos e pacotes turísticos formatados pelas operadoras turísticas. No final da cadeia está o consumidor final, ou seja, o turista.

Assim como na cadeia produtiva do agronegócio, a cadeia produtiva do turismo também é afetada negativamente e/ou positivamente por fatores externos, a saber: culturais; institucionais ou legais; tecnológicos; ambientais, infra-estrutura e econômicos.

Nos Fatores Culturais estão alocados impactos de aculturação, motivação (subentendendo como meios de motivar o deslocamento de determinados segmentos) e capacitação profissional. Os Fatores Institucionais e Legais envolvem os financiamentos, regulamentação da atividade, impostos e a elaboração e execução de políticas voltadas a atividade turística. Estão incluídos ainda os aspectos relacionados a legislação do turismo (específica da 
atividade turística) e a legislação para o turismo (as outras legislações que afetam diretamente o desempenho da atividade). Por sua vez, os Fatores Tecnológicos referem-se ao desenvolvimento e a utilização de softwares específicos e de pesquisas técnico-científicas e de mercado.

No que se refere à Fatores Ambientais, grande foco na atualidade, inserem-se a poluição, as intempéries, a degradação e a valorização da paisagem. Considerando a diversidade e fragilidade ambiental em Mato Grosso do Sul, principalmente nos destinos Corumbá e Bonito, ações adicionais às existentes de preservação do meio ambiente devem ser tomadas para assegurar a qualidade ambiental dessas regiões. Em Corumbá o turismo de pesca (a principal atividade turística do destino) é afetado pelo período da piracema, quando é proibida a pesca nos rios do Estado. Em Bonito, a delimitação da capacidade de carga e obrigatoriedade da realização de licenciamento ambiental dos empreendimentos são fatores extremamente importantes para garantir a qualidade ambiental e o valor da paisagem. Medidas como as descritas acima afetam o turismo, mas são de extrema importância para assegurar que os recursos naturais (grande motivador dos fluxos turísticos) sejam conservados. Logo, o turismo deve se adaptar a essas situações para permitir o seu próprio desenvolvimento.

Nos Fatores de Infra-estrutura estão alocados o acesso, o transporte, a comunicação e os serviços bancários - que fazem alusão aos diversos outros serviços. Tudo isto se complementa em Fatores Econômicos, estando neles alocados os elementos: taxa cambial e valorização da moeda.

Por fim, como Mecanismos de Coordenação considerou-se o poder público, a iniciativa privada e o mercado. No Mato Grosso do Sul, verifica-se que em cada pólo turístico, a coordenação é feita por um ator, a saber: em Campo Grande a governança da cadeia é dividida entre poder público e iniciativa privada; em Bonito é a iniciativa privada que exerce a governabilidade, sendo que agora o poder público começa a tomar frente em algumas ações, principalmente em ações voltadas para garantir a qualidade ambiental do destino; já em Corumbá, a cadeia produtiva do turismo é controlada pelo poder público, uma vez que, grande parte das ações de fomento, marketing e eventos que movimentam a atividade turística da região são concretizadas pelo poder público municipal.

Ao longo da pesquisa foram identificados pontos fortes e fracos que afetam o desempenho da cadeia do turismo em Mato Grosso do Sul, a saber: 
a) Pontos fortes:

- Grande potencial turístico (recursos naturais e culturais);

- O Estado já dispõe de três pólos turísticos bem estruturados e tem capacidade para desenvolver outras regiões turisticamente;

- Nos últimos anos, Mato Grosso do Sul vem sendo divulgado e promovido em eventos nacionais e internacionais;

- Possui algum apoio governamental para o fomento do turismo;

- Disponibiliza infra-estrutura para receber eventos de pequeno e médio porte nos três pólos turísticos já desenvolvidos;

- Existência dos Conventions Bureaux. Em 2007, o Estado possui três convetions bureaux, sendo que Corumbá, já se articula para a criação de um convention bureau para a região. Os convention bureaux existentes são: Campo Grande Pantanal Convention \& Visitors Bureau; Bonito Convention \& Visitors Bureau; e Grande Dourados Convention \& Visitors Bureau;

- Ações que permitem a diversificação da atividade turística (turismo de eventos, de negócios, ecoturismo, turismo de pesca);

- Localização estratégica: o Estado faz divisa com cinco outros estados e mais dois países;

- Aumento no fluxo de movimentação de pessoas no Estado. Considerando apenas o fluxo de pessoas que chegam ao Estado utilizando o transporte aéreo, de 2004 para 2005, o aumento foi de 135.656 pessoas, segundo dados divulgados pela INFRAERO em 2006.

b) Pontos fracos:

- Desarticulação empresarial;

- Ausência de cultura cooperativa ao longo da cadeia;

- Falta de integração entre os elos da cadeia;

- Desarticulação entre os principais destinos turísticos;

- Realização de ações de marketing isoladas; 
- Informalidade/ilegalidade de empresas;

- A pouca oferta de horários e rotas oferecidas pelo transporte aéreo;

- Ausência de companhias aéreas regionais;

- Sazonalidade;

- Baixa qualificação da mão-de-obra que atua nos empreendimentos hoteleiros, agências de turismo, restaurantes e no comércio. É necessário aumentar o número de profissionais que tenham fluência em outro idioma; melhorar o atendimento ao turista e motivar os funcionários a conhecer a história e especificidades do destino e produtos comercializados, bem como aumentar o número de profissionais com cursos técnicos e formação superior.

- Ausência de dados econômicos do setor;

- Prostituição infanto-juvenil.

Além dos pontos fortes e fracos são apontadas algumas situações de conflito verificadas que afetam diretamente o desempenho da cadeia produtiva do turismo do Mato Grosso do Sul, a saber:

1) Situação de Conflito entre Destino Mato Grosso do Sul e Companhia aéreas

Os meios de acesso são determinantes para a sobreposição de um destino turístico perante os outros. Mato Grosso do Sul, enfrenta essa dificuldade de acesso no que tange ao transporte aéreo, tendo em vista a pouca oferta de vôos disponibilizados pelas companhias aéreas para o Estado. Além disso, Mato Grosso do Sul não possui companhias aéreas regionais, bem como a atuação de companhias aéreas externas que poderiam suprir e até estimular a demanda, operando vôos que partissem de Campo Grande (principal portão de entrada do Estado) com destino as outras localidades turísticas do estado, como por exemplo, Bonito e Corumbá. Tal fato contribuiria para a diminuição do tempo de viagem e daria mais autonomia aos destinos, haja vista que, se tornariam mais independentes das companhias aéreas nacionais, que necessitam de grande demanda para abertura de novas rotas.

2) Situação de Conflito entre poder público e o desenvolvimento da atividade turística

A priorização de algumas regiões do Estado para a realização de investimentos públicos para o desenvolvimento do turismo pode gerar conflitos entre as prefeituras municipais de regiões 
menos priorizadas e o poder público estadual. Essa priorização é negativa, pois impede, de certa forma, a diversificação da atividade turística no Estado e o desenvolvimento de outros pólos turísticos.

É válido mencionar, ainda, que a atividade turística, também é afetada por interesses políticos. O Estado já vivenciou situações em que eventos e projetos que estavam sendo realizados em determinada gestão foram completamente abandonados durante a troca de mandato. Essa instabilidade política compromete o desenvolvimento da atividade turística, uma vez, que não há continuidade nos processos iniciados anteriormente.

3) Situações de conflito entre setor público e privado quanto ao fornecimento de dados sobre a atividade turística

Compreender o setor de turismo de forma quantitativa é essencial para seu desenvolvimento e para busca de financiamento de novos projetos e ações. Mato Grosso do Sul ainda não possui um sistema efetivo para coleta de dados relacionados ao turismo. Os dados existentes ainda são esparsos e de pouco confiabilidade. A ilegalidade de algumas empresas que atuam no setor contribui para essa situação, uma vez que, estas não existem para os órgãos oficiais, ficando ausentes das estatísticas e dos números do setor.

4) Situações de Conflito entre as Operadoras e as outras empresas turísticas

As operadoras de turismo são as responsáveis pela formatação do pacote turístico. A existência de preços diferenciados por parte das outras empresas prestadoras de serviços é essencial para garantir a criação de pacotes turísticos de qualidade e com valores competitivos no mercado. Em Mato Grosso do Sul, observa-se grande dificuldade de entendimento por parte dos outros prestadores de serviços da cadeia, em trabalharem com tabela de preços diferenciados junto às operadoras. A grande maioria dos empresários prefere, muitas vezes, oferecer diretamente ao turista uma tarifa reduzida, ao invés de oferecer essa tarifação às operadoras, que poderão repassar esses custos a um maior número de clientes, tendo em vista que os pacotes turísticos são organizados em média para grupos mínimos de 20 pessoas.

A não diferenciação das tarifas é prejudicial ao turismo do Estado uma vez que dificulta a organização de pacotes turísticos de qualidade e com preços competitivos junto às outras destinações brasileiras. Além do mais, conforme dito por Batalha (2001) e Pinheiro et al (2005), o estabelecimento de alianças dentro da cadeia é determinante para o sucesso e a competitividade desta. Para tanto, é importante formar alianças estratégicas, acordos 
cooperativos do tipo ganha-ganha, mesmo que os objetivos estratégicos dos agentes da cadeia não sejam iguais, contanto que sejam complementares.

5) Situação de Conflito entre o transporte rodoviário alternativo e os órgãos regularizadores

Campo Grande é o principal portão de entrada para os turistas que vistam Bonito e a região do Pantanal. A não regularização do transporte de passageiros utilizando veículos privados é um problema para o turismo no Estado, tendo em vista, que a utilização do transporte rodoviário intra-estadual, em alguns casos, torna-se inviável devido a incompatibilidade dos horários de chegada dos vôos e saída dos ônibus. Além disso, deve-se considerar o tempo de deslocamento até o outro destino. Para diminuir o tempo de deslocamento, bem como, garantir a qualidade da viagem e a satisfação do cliente é que operadoras já incluem em seus pacotes os serviços de translado desde Campo Grande.

A falta de regularização pode vir a comprometer a qualidade dos serviços oferecidos, já que há pouca fiscalização das empresas que oferecem esses serviços, bem como, existe a possibilidade da suspensão da atividade, o que pode afetar a satisfação do turista que visita o Estado.

6) Situações de conflito entre a Agência de turismo e os outros agentes do trade

A organização e a realização de uma viagem demandam o envolvimento de um grande número de atores. A agência de turismo, por ser a empresa que tem contato direto com o cliente e responsável pela venda do produto turístico, mesmo não sendo a prestadora de todos os serviços, fica sendo a empresa responsável por garantir a qualidade do serviço prestado, uma vez, que é a ela que o turista vai recorrer caso, ocorra algum problema durante a viagem.

A falta de profissionalismo dos agentes prestadores de serviços compromete a qualidade dos serviços prestados, e, por conseguinte, a qualidade do serviço prestado pela agência e até mesmo a imagem da empresa junto ao público em geral.

As situações demonstradas indicam que a organização do turismo em Mato Grosso do Sul ainda é incipiente. A ausência de uma política estadual de turismo também contribui para a situação mencionada, uma vez que não são estabelecidas as diretrizes e as prioridades para o desenvolvimento da atividade turística no Estado. É possível afirmar que problemas relacionados tanto à infra-estrutura básica (acesso, saneamento, comunicações etc.) e infraestrutura turística (hospedagem, agenciamento, alimentação, entretenimento etc.) quanto a capacitação profissional da mão-de-obra local são os principais gargalos da cadeia do turismo 
do Estado, constituindo-se assim em entraves para a formatação de produtos turísticos de qualidade e competitivos.

\section{Considerações Finais}

Analisar e compreender o turismo utilizando a ferramenta de análise de cadeia de produção ainda é recente no Brasil, todavia, conforme descrito por Massari (2005) é determinante para garantir a efetiva organização do setor. A caracterização da cadeia produtiva do turismo do Mato Grosso do Sul realizada neste estudo, vem ao encontro dessas necessidades, uma vez que buscou identificar e alocar os agentes atuantes no setor. Isto foi complementado, estabelecendo sua lógica de produção, bem como, pontuando os principais pontos fortes e fracos e as situações de conflito que afetam positivamente e negativamente a relação desses atores.

Apesar da organização do turismo em Mato Grosso do Sul ser ainda recente, observa-se a existência de três pólos turísticos principais que trabalham isoladamente a fim de garantir o fluxo turístico para determinada localidade, o que fragiliza a imagem de Mato Grosso do Sul como destino turístico. Tal situação diminui a competitividade perante os outros destinos turísticos nacionais e internacionais e é gravada pela ausência de uma política estadual de turismo.

Dentro desse contexto, conclui-se que os gargalos apresentados apontam para necessidade uma maior cooperação entre poder público e a iniciativa privada, maior qualificação e capacitação da mão-de-obra, maior articulação entre os agentes envolvidos e aumento nos investimentos em infra-estrutura (básica e turística).

\section{Referências}

ABREU, Cristiane Buhamra. 2002. Turismo além do "sol e praia": uma análise na cidade de Fortaleza. Fortaleza: SENAC/SEBRAE - CE.

BARRETO, Margarida. 2003. Planejamento e Organização em Turismo. 9 ed. Campinas: Papirus.

BALANZÁ, Isabel Milio; NADAL, Mónica Cabo. 2003. Marketing e Comercialização de Produtos Turísticos. São Paulo: Pioneira Thomson Learning.

BATALHA, Mário Otávio. 2001. Gestão agroindustrial. 2. ed. v. 1. São Paulo: Atlas.

BENI, Mário. 2003. Análise estrutural do turismo. 8. ed. São Paulo: Editora Senac São Paulo.

CORDEIRO, Nadir Radoll. 2001. Construção de um modelo de gestão estratégica para organizações prestadoras de serviços utilizando o Balanced Scorecard, o gerenciamento de processos e o 
Marketing de Relacionamentos. 182 f. Dissertação (Engenharia de Produção) - Universidade Federal de Santa Catarina. Disponível em: <http://teses.eps.ufsc.br/defesa/pdf/4363.pdf $>$. Acesso em: 03 mai. 2006.

EMBRATUR. Anuário Estatístico 2004. Brasília, julho de 2004. Disponível em: $<$ http:www.turismo.gov.br>. Acesso em: 20 de mar. 2006.

. 2005. Anuário Estatístico da EMBRATUR 2005. v. 32. Brasília: MTUR. Dados 2004.

2005. Indicadores do Turismo Nacional. Disponível em:

$<$ http://www.turismo.gov.br/site/br/dados_fatos/conteudo/lista.php?in_secao=303>. Acesso em: 09 mai. 2006.

FLEURY, Afonso; FLEURY, Maria Tereza. Em busca de metodologias para o estudo da cadeia de valor. In: GITHAY, Leda; LEITE, Márcia de Paula. (orgs). 2005. Novas Tramas Produtivas: uma discussão teórico-metodológica. São Paulo: Editora Senac, p. 149-169.

IBGE. s/d. Disponível em: <http://www.ibge.gov.br/>. Acesso em: 20 de mar. 2006.

INFRAERO. Aeroporto Internacional de Campo Grande. Disponível em: $<$ http://www.infraero.gov.br/aero_prev_comp_aero.php?ai=76>. Acesso em: 20 jul. 2006.

JÚNIOR, O. 2006. Turismo em MS cresce acima da média nacional. Correio do Estado. Campo Grande: 21 jan. 2006. Disponível em: <http://www.correiodoestado.com.br/exibir.asp?chave=120982,1,3,2101-2006>. Acesso em: 21 mar. 2006.

MASSARI, Cristina. 2005. Cadeia produtiva do turismo: modelos para análise e reflexão. Rio de Janeiro: Senac Nacional.

MICHELS, Ido Luiz; PROCHMANN, Angelo Mateus. 2003. Psicultura. Campo Grande: Ed. UFMS. (Coleção Cadeias Produtivas de Mato Grosso do Sul; 8.).

MINISTÉRIO DO DESENVOLVIMENTO, INDÚSTRIA E COMÉRCIO EXTERIOR. SECRETARIA DO DESENVOLVIMENTO DA PRODUÇÃO. Fónum de Competitividade. Brasilia, dez 2004. Disponível em: $<$ http://www.desenvolvimento.gov.br/arquivo/sdp/forCompetitividade/doBasmetodologia.doc $>$ Acesso em: 19 nov. 2006.

. Fóruns de Competitividade. 2002. Brasília.

MINISTÉRIO DO TURISMO. Caracterização e dimensionamento do turismo doméstico no Brasil Apresentação dos primeiros resultados. Rio de Janeiro, 16 mar. 2006. Disponível em: $<$ http://www.turismo.gov.br>. Acesso em: 20 de mar. 2006.

29 mar. 2006.

Cadastro de Turismo. Disponível em: < http://www.cadastro.turismo.gov.br/>. Acesso em:

. Plano Nacional de Turismo. 2003. Brasília.

. Programa de Regionalização do Turismo. Disponível em:

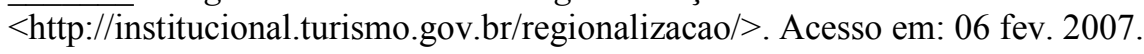

- Relatório Estatístico da Posição do Cadastro Prestadores de Serviços Turísticos. Disponível em: <http://www.extranet.turismo.gov.br/main.asp>. Acesso em: 15 mai. 2006 às $10 \mathrm{~h} 19 \mathrm{mim} 42 \mathrm{seg}$.

Turismo no Brasil 2007-2010. 2006. Brasília.

PINHEIRO, Luiz Eustáquio Lopes, PINHEIRO, Lucas Augusto Soeiro, BRUM, Eron, PEREIRA, Francisco Assis Rolim, LEITE, Francisco Carlos Trindade, PINHEIRO, Leonardo Soeiro. Pesquisa Cooperativa na Produção Agroindustrial - A Criação de um Novo Modelo. In: BAUER, Fernando César; VARGAS JUNIOR, Fernando Miranda de. 2005. Produção e Gestão Agroindustrial. Campo Grande: Editora UNIDERP.

ORGANIZAÇÃO MUNDIAL DO TURISMO. 2001. Introdução ao turismo. São Paulo: Roca. 
SEBRAE.

Cadeias

produtivas.

Disponível

em:

$<$ http://www.sebrae.com.br/br/cooperecrescer/cadeiasprodutivas.asp> Acesso em: 19 nov. 2006.

SECRETARIA DE ESTADO DE PLANEJAMENTO E DE CIÊNCIA E TECNOLOGIA (SEPLANCT). Diagnóstico socioeconômico de Mato Grosso do Sul, 2003. Campo Grande, 2003. 106 p. Disponível em: <http://www.msemnumeros.com.br/msemnumeros3/public/informacoes/

arquivo_informacao164.pdf>. Acesso em: 21 ago. 2006.

PIB/MS Produto Interno 1985-2004. Campo Grande, 2006. Disponível em: $<\mathrm{http} / /$ www.seplanct.ms.gov.br/index.php?inside=1\&tp=3\&comp=\&show=713>. Acesso em: 05 fev. 2007.

SILVEIRA, Fernanda. Fluxo de turistas cresce em 23,9\% no Estado, diz Nilde Brun. Capital do Pantanal. Corumbá: 20 jan. 2006. Disponível em: $<$ http://www.capitaldopantanal.com.br/index.php?sPagina $=$ cpt002_noticia\&iNoticia $=1552 \&$ sCanal=>. Acesso em: 21 mar. 2006.

ZIMERMANN, Adonis. 1996. Turismo rural: um modelo brasileiro. Florianópolis: Ed. do autor.

Recebido em: 20/06/2007 (1 ${ }^{\mathrm{a}}$ versão) $16 / 07 / 2008$ ( $2^{\mathrm{a}}$ versão)

Aprovado em: 10/12/2008 